\title{
BMJ Open Household survey analysis of the impact of comprehensive strategies to improve the expanded programme on immunisation at the county level in western China, 2006-2010
}

\author{
Yuqing Zhou, ${ }^{1}$ Yi Xing, ${ }^{2}$ Xiaofeng Liang, ${ }^{1}$ Chenyan Yue, ${ }^{1}$ Xu Zhu, ${ }^{3}$ David Hipgrave ${ }^{4}$
}

To cite: Zhou Y, Xing $Y$, Liang $X$, et al. Household survey analysis of the impact of comprehensive strategies to improve the expanded programme on immunisation at the county level in western China, 2006-2010. BMJ Open 2016;6:e008663. doi:10.1136/bmjopen-2015008663

- Prepublication history and additional material is available. To view please visit the journal (http://dx.doi.org/ 10.1136/bmjopen-2015008663).

$Y Z$ and $Y X$ are joint first authors.

Received 24 September 2015 Revised 21 December 2015 Accepted 13 January 2016

CrossMark

For numbered affiliations see end of article.

Correspondence to Dr Xiaofeng Liang; liangxf@hotmail.com and Dr David Hipgrave; dhipgrave@gmail.com

\section{ABSTRACT}

Objective: To evaluate interventions to improve routine vaccination coverage and caregiver knowledge in China's remote west, where routine immunisation is relatively weak.

Design: Prospective pre-post (2006-2010) evaluation in project counties; retrospective comparison based on 2004 administrative data at baseline and surveyed postintervention (2010) data in selected non-project counties.

Setting: Four project counties and one non-project county in each of four provinces.

Participants: 3390 children in project counties at baseline, and 3299 in project and 830 in non-project counties post-intervention; and 3279 caregivers at baseline, and 3389 in project and 830 in non-project counties post-intervention.

Intervention: Multicomponent inexpensive knowledge-strengthening and service-strengthening and innovative, multisectoral engagement.

Data collection: Standard 30-cluster household surveys of vaccine coverage and caregiver interviews pre-intervention and post-intervention in each project county. Similar surveys in one non-project county selected by local authorities in each province postintervention. Administrative data on vaccination coverage in non-project counties at baseline.

Primary outcome measures: Changes in vaccine coverage between baseline and project completion (2010); comparative caregiver knowledge in all counties in 2010.

Analysis: Crude $\left(\chi^{2}\right)$ analysis of changes and differences in vaccination coverage and related knowledge. Multiple logistic regression to assess associations with timely coverage.

Results: Timely coverage of four routine vaccines increased by $21 \%(p<0.001)$ and hepatitis B ( HepB) birth dose by $35 \%(p<0.001)$ over baseline in project counties. Comparison with non-project counties revealed secular improvement in most provinces, except new vaccine coverage was mostly higher in project counties. Ethnicity, province, birthplace, vaccination site, dual-parental out-migration and parental knowledge had significant associations with coverage.
Strengths and limitations of this study

- The study evaluated routine service strengthening and innovative multisectoral engagement in 16 counties in remote western China.

- Standard household survey methods were used to evaluate vaccine coverage and caregiver knowledge.

- An attempt to assess secular changes in vaccination coverage was included, but interpretation is limited by lack of survey data and use of administrative data for non-project sites at baseline.

- By contrast, confidence in the observed impact of the interventions remains high for the coverage of vaccines introduced after the start of the project, and for the householder knowledge variables assessed.

Knowledge increased for all variables but one in project counties (highest $p<0.05$ ) and was substantially higher than in non-project counties $(p<0.01)$.

Conclusions: Comprehensive but inexpensive strategies improved vaccination coverage and caretaker knowledge in western China. Establishing multisectoral leadership, involving the education sector and including immunisation in public-sector performance standards, are affordable and effective interventions.

\section{INTRODUCTION}

The global Expanded Program on Immunization (EPI) was launched in 1974, ${ }^{1}$ and has significantly reduced the incidence of measles, polio and newborn tetanus. ${ }^{2-4}$ China's EPI started in 1978 and currently includes BCG, oral polio (OPV), diphtheria/ tetanus/pertussis (DTP), hepatitis B (НерB), Japanese encephalitis (JEV), hepatitis A (HAV), measles (MV) or measles/mumps/ rubella (MMR) and meningococcal (MenV) vaccines. $^{5} 6$ 
However, financial and social sector decentralisation ${ }^{7}$ and variable geographic and socioeconomic conditions in China result in uneven access to health services, including vaccination. ${ }^{8}$ For example, in 2004, administration of the HepB birth dose was less often timely in western $(49.5 \%)$ than central $(72.7 \%)$ and eastern $(81.9 \%)$ regions $^{9}$; we previously described variable coverage with this vaccine according to several related variables. ${ }^{10}$ Ongoing measles transmission and the 2011 outbreak of imported poliovirus in western China ${ }^{11}$ indicate that children there remain vulnerable to vaccinepreventable diseases, due to relatively low access to and knowledge of the EPI.

To improve routine vaccination coverage in western areas similar to those periodically affected by vaccinepreventable disease outbreaks, from mid-2006 to mid-2010, UNICEF supported China's Ministry of Health (through China's Centre for Disease Control (CDC) and local counterparts) to implement an EPI-strengthening project in four western provinces (Guangxi, Guizhou, Tibet and Shaanxi), housing 8.7\% of China's population. ${ }^{12}$ The objective was to strengthen the routine EPI in these provinces by increasing its prioritisation for local funding and policy support, enhancing related service capacity and increasing caregivers' demand for EPI services. The goal was to narrow the gap in coverage between China's eastern and western regions, reducing the risk of disease outbreaks and improving equity. While there are reports on a healthcommunication approach to improving EPI coverage in China, ${ }^{13}$ this project involved multiple sectors, predicting the growing focus on a systems approach to health service strengthening, as opposed to simply supporting services with supplies, personnel and training. ${ }^{14}$ Only one similar and much smaller project has been described in China. ${ }^{15}$

To independently evaluate EPI coverage and related knowledge and associations in project and non-project sites, to assess the project's impact on EPI access and uptake, and to provide guidance for other counties in China's west, baseline and final evaluations of the project were conducted. We describe the project's impact on vaccine coverage and related caregiver knowledge, associations with families not utilising vaccination services, and explain how the project inputs and strategy influenced the observed outputs.

\section{METHODS}

\section{Project location and strategy}

Guangxi, Guizhou, Tibet and Shaanxi provinces have 109, 88, 76 and 80 counties, respectively. Project funding permitted implementation in only four counties in each province, with a total population of 4.04 million. ${ }^{10}$ The criteria for county selection were developed by China CDC and included average Gross Domestic Product per capita (predominantly very low), the rate of timely birth dosing with $\mathrm{HepB}$ and of full coverage with the four traditional EPI vaccines (BCG, OPV, DTP and MV) as defined by the WHO and UNICEF, ${ }^{16}{ }^{17}$ measles incidence and the hospital delivery rate in 2004 (table 1). The 16 counties were selected by the four province offices of the $\mathrm{CDC}$, whose staff also used local knowledge of EPI implementation, prioritisation and quality. Staff members were instructed to purposively select counties considered representative of average EPI performance based on these criteria.

The project components collectively comprised a comprehensive approach to EPI strengthening: (1) advocacy to increase awareness and funding of the EPI among local leaders, planners and finance officers; (2) EPI standard-setting according to national guidelines and local conditions; (3) training of EPI and health staff at county, township and village levels, using nationally developed materials; (4) flexible communication strategies adapted to different target populations including women of reproductive age and pregnant women (PW), to increase demand; (5) cold chain, computer and public communication equipment and (6) activities to improve cooperation between local health, education and other sectors and among communities. These components were based on global recommendations ${ }^{17}{ }^{18}$; more details are provided in web-annex 1. UNICEFsupported project implementation costs averaged approximately $\$ 14000$ per county per year, apart from the surveys reported here; local government covered the balance of project expenses.

The project promoted hospital delivery according to China's national Safe Motherhood Program (SMP), and the HepB birth dose in all project county maternity units. China's SMP was phased in over 2002-2010, and provides subsidised (usually free) hospital delivery along with related information to rural women. ${ }^{19}$ Village doctors are paid a small incentive (around US\$1.5) to identify and inform $\mathrm{PW}$ of this programme. In project counties where nationally funded subsidies and incentives had not yet started, local government provided the same benefits. Village doctors provided PW with information on immunisation, and maternal and child health, and were also responsible for procuring and administering the HepB birth dose to newborns delivered at home.

\section{Evaluation strategy}

Baseline and final household surveys were conducted in project counties in 2006 and 2010. In 2006, local EPI services were also assessed through health facility surveys, facilitating project design. Similar surveys were conducted in the non-project counties, in 2010.

To assess the project's impact over time, we surveyed selected indicators in project counties at baseline in 2006 and at project completion in 2010. Each survey assessed vaccine coverage, related knowledge, attitudes and practices (KAP) of caregivers, immunisation 
Table 1 Key indicators in project and non-project counties in 2004

\begin{tabular}{|c|c|c|c|c|c|c|}
\hline County & $\begin{array}{l}\text { Population } \\
(10000)\end{array}$ & $\begin{array}{l}\text { GDP per } \\
\text { capita (RMB) }\end{array}$ & $\begin{array}{l}\text { Timely } \\
\text { HepB1 (\%) }\end{array}$ & $\begin{array}{l}\text { Traditional } \\
4 \text { vaccines } \\
\text { coverage* }^{*}\end{array}$ & $\begin{array}{l}\text { Measles } \\
\text { incidence } \\
(1 / 100000)\end{array}$ & $\begin{array}{l}\text { Hospital } \\
\text { delivery } \\
\text { rate (\%) }\end{array}$ \\
\hline \multicolumn{7}{|l|}{ Guangxi } \\
\hline Donglan & 28.1 & 2491 & 23.3 & 90.6 & 0.0 & 35.5 \\
\hline Luocheng & 36.2 & 3124 & 58.7 & 86.5 & 0.3 & 70.3 \\
\hline Sanjiang & 35.3 & 2287 & 34.7 & 89.6 & 2.9 & 31.2 \\
\hline Napot & 19.6 & 2380 & 22.2 & 90.0 & 1.6 & 40.1 \\
\hline Tianlin $\ddagger$ & 23.9 & 3719 & 19.7 & 87.8 & 4.3 & 37.6 \\
\hline \multicolumn{7}{|l|}{ Guizhou } \\
\hline Taijiang & 14.0 & 2200 & 11.2 & 65.1 & 18.6 & 13.4 \\
\hline Luodian & 31.7 & 1231 & 10.6 & 73.1 & 0.0 & 23.8 \\
\hline Changshun & 24.5 & 1561 & 10.9 & 66.3 & 0.4 & 45.0 \\
\hline Jianhe† & 24.3 & 1989 & 11.8 & 47.4 & 36.8 & 30.0 \\
\hline Huangpingf & 35.4 & 1478 & 11.5 & 75.5 & 2.1 & 26.6 \\
\hline \multicolumn{7}{|l|}{ Tibet } \\
\hline Qusong & 1.6 & 2217 & 11.8 & 83.9 & 0.0 & 21.5 \\
\hline Anduo & 3.6 & 2710 & 36.7 & 91.2 & 0.0 & 57.3 \\
\hline GBJD & 2.6 & 3090 & 30.0 & 97.5 & 0.0 & 31.5 \\
\hline Jiangzi† & 6.2 & 6927 & 12.5 & 94.6 & 2.0 & 66.2 \\
\hline Nanmulin $\ddagger$ & 7.5 & 2716 & 8.5 & - & 0.0 & 4.6 \\
\hline \multicolumn{7}{|l|}{ Shaanxi } \\
\hline Qianxian & 55.9 & 4725 & 22.2 & 44.4 & 0.9 & 90.0 \\
\hline Fuping & 76.1 & 2505 & 30.1 & 65.3 & 1.4 & 89.3 \\
\hline Jingbian & 28.6 & 17804 & 40.0 & 56.0 & 18.7 & 81.3 \\
\hline Ansai† & 16.2 & 16498 & 61.1 & 30.1 & 12.6 & 74.6 \\
\hline Yanchuan $\ddagger$ & 18.1 & 23400 & 68.9 & 70.0 & 49.6 & 91.5 \\
\hline
\end{tabular}

services, socioeconomic status, demographic variables, mothers' education and parental out-migration. To assess secular changes, we requested each province to select one reference project county for comparison with one non-project county from the same prefecture, having broadly similar EPI performance, management and local government support, and similar population size and composition, geography and socioeconomic status, in 2004 (table 1). It was not possible to directly compare changes in EPI coverage in non-project counties, as we could not survey those counties in 2006; however, 2004 administrative vaccine coverage data were available for three of the four non-project counties at baseline. Vaccine coverage and householder KAP in both, the reference project county and selected nonproject counties, were compared in 2010, using identical survey methods in each.

The baseline household and health facility surveys were implemented from September to November 2006, by China CDC and UNICEF. The follow-up household survey was conducted from March to November 2010, by Peking University's Institute of Child and Adolescent Health (ICAH), supported by China CDC and UNICEF, using a questionnaire in all surveyed counties. Developed by China CDC, the questionnaire included the same content in 2006 and 2010. EPI coverage and
KAP were assessed during interviews with the selected child's mother or primary caregiver.

Ethical approval to conduct the project and surveys was provided by an independent panel at China CDC and by local authorities.

\section{Location and sampling}

For each survey, the WHO standard EPI cluster survey methodology was followed. ${ }^{20}$ In each county, two-stage cluster sampling was used to first select 30 clusters (villages), with a probability of selection according to each village's population size. In the second stage, seven children born anytime in 2004 (for the 2006 survey), and between 1 June 2007 and 31 May 2008 (for the 2010 survey), were selected in series, beginning by randomly selecting a dwelling from a numbered list of households, finding the nearest age-appropriate child, followed by the next closest, and continuing for up to seven from each cluster. This yielded 210 children per county and a coverage precision of $\pm 10 \% .^{20}$ In Tibet, where the population is very sparse, 10 townships were selected randomly in each county, and all children born during the same dates were investigated. The investigation in each county ended when samples reached 210. 


\section{Data collection}

Vaccination records were reviewed at households, using certificates (kept by mothers/caregivers) and cards (brought by EPI providers from health facilities to surveyed households). Surveyors relied on the certificate if both records were available; if neither was available, the child was considered unvaccinated. BCG scars were assessed on site. Small gifts were provided to caregivers; there were no refusals. Surveyors applied the following criteria for age-appropriate vaccination: birth and inoculation dates recorded correctly; first dose administered at the appropriate age; dose interval $\geq 28$ days for OPV and DTP; BCG, OPV3 (the third dose of OPV) and DTP3, and MV1 received before age 12 months, and the certificate or card fully completed. The WHO definition for fully immunised children (FIC) was used. ${ }^{18}$ 'Timely' HepB1 is within $24 \mathrm{~h}$ of delivery, and HepB3 by age 12 months ${ }^{16}$; booster (fourth) dose of DTP and second dose of measles-containing vaccine (MV or MMR) administered between 18-24 months were considered age appropriate.

\section{Quality control}

ICAH and national EPI experts developed the 2010 survey implementation protocol, trained investigators and analysed the data. Pilots were conducted and the process was adjusted before the start. Trained staff from the ICAH, and from provincial and prefecture offices of the CDC, undertook the survey and questionnaire.

\section{Data analysis}

All data were double-entered into EpiData3.1 (USCDC, Atlanta, Georgia, USA), and checked for consistency. Cleaned data were analysed using SPSS V.13.0 (Chicago, Illinois, USA); crude comparisons between reference project and selected non-project counties were made using the $\chi^{2}$ test. Multiple logistic regression was used to assess associations with timely coverage of BCG, OPV, DTP and MV. Potential influences on EPI coverage were assessed; those significantly associated $(\mathrm{p} \leq 0.10)$ during univariate backwards regression using the Wald test were retained. ORs adjusted for the influence of other variables were calculated in a multivariate regression model. Statistical significance was set at $\mathrm{p} \leq 0.05$, and was two-tailed.

\section{RESULTS}

\section{Basic information}

In total, 3390 child/caregiver pairs were surveyed in project counties at baseline, and 4129 in project and non-project counties, in 2010. During the same year, 70 pairs were excluded as the children were the wrong age; there had been no such exclusions in 2006. Among those remaining in 2010, $3299(79.9 \%)$ lived in project counties, and $830(20.1 \%)$ in non-project counties. The majority of children in Guangxi, Guizhou and Tibet belonged to one of China's ethnic minorities; virtually all in Shaanxi province were Han ethnicity. The majority $(91.1 \%)$ lived in rural areas; most children $(98.1 \%)$ were local residents (table 2). The male:female ratio was
1.29:1. These characteristics were similar to those collected at baseline (data not shown). Project reference and non-project counties were poorly matched on some parameters (table 1), but local CDCs considered their respective EPIs qualitatively similar. The hospital delivery rate in project counties was $50 \%$ in 2004 and $90.2 \%$ in 2010; in non-project counties it was $42 \%$ in 2004 and $88 \%$ in 2010.

\section{Vaccine coverage}

Vaccine coverage in 2010 and changes from baseline in project counties, calculated using recommended methods, ${ }^{20}$ are presented for some vaccines in table 3 , and for all vaccines in web-annex 2. Surveyed 2006 baseline coverage in most counties was close to the 2004 administrative data provided (table 1), encouraging cautious use of 2004 administrative data for non-project counties. Compared to baseline, the coverage of timely HepB1 in project counties increased the most (by $35.2 \%$ overall, and $58.6 \%$ in one county). Full, timely coverage with the four traditional vaccines increased by $21.1 \%$. Coverage of HepB3, DTP3, OPV3, BCG and MV all increased significantly, and the proportion of children with a BCG scar rose $12.9 \%$ (table 3; web-annex 2). Large increases in FIC were particularly evident in Guizhou and Shaanxi. However, FIC decreased by $16.3 \%$ in one remote Tibetan county where EPI access remains very infrequent.

Vaccine coverage in 2010 was usually higher in the reference project counties than in the selected non-project county, in many cases significantly so (table 3). This was particularly true for timely coverage of HepB1 and the newly integrated EPI vaccines (DTP and measles boosters and MenV in most provinces; and JEV and HAV in two provinces each) (table 3 and web-annex 2). The BCG scar rate was also significantly higher in project than in non-project counties in Tibet and Shaanxi. The observed differences in coverage of the four traditional vaccines were mostly not present at baseline (table 1 ).

\section{Changes in KAP}

There were major and significant changes in the proportion of project county mothers/caregivers with basic EPI knowledge (table 4 and web-annex 3). Knowledge increased by $\geq 22 \%$ for each item, with $56.7 \%$ more knowing that vaccination status is checked at kindergarten- and school-entry. The knowledge of mothers/caregivers in Tibet increased most, despite high baseline EPI coverage in Tibetan project counties. Significantly more caregivers in project than in nonproject counties had EPI-related knowledge, especially related to vaccines required at birth and observation time after vaccination (table 4 ).

\section{Influences on FIC rate}

Influences on FIC rates were assessed using multivariate analysis that first took account of ethnicity; place of birth, residence and vaccination; maternal education and age; parents' migration status and EPI-related 
Table 2 Number, gender, residence type and citizenship of children surveyed in 2010 (\%)

\begin{tabular}{|c|c|c|c|c|c|c|c|c|c|}
\hline \multirow[b]{2}{*}{ Location } & \multirow{2}{*}{$\begin{array}{l}\text { Number } \\
\text { surveyed }\end{array}$} & \multicolumn{2}{|c|}{ Gender (\%) } & \multicolumn{3}{|c|}{ Residence type (\%) } & \multicolumn{3}{|c|}{ Citizenship (\%) } \\
\hline & & Male & Female & County & Township & Village & Local & Non-local & Other \\
\hline Guangxi & 1046 & 56.7 & 43.3 & 6.1 & 5.3 & 88.6 & 99.0 & 1.0 & 0.0 \\
\hline Donglan & 210 & 58.6 & 41.4 & 6.7 & 1.9 & 91.4 & 98.1 & 1.9 & 0.0 \\
\hline Luocheng & 209 & 52.6 & 47.4 & 6.7 & 12.0 & 81.3 & 99.5 & 0.5 & 0.0 \\
\hline Sanjiang & 207 & 56.0 & 44.0 & 3.4 & 5.8 & 90.8 & 100.0 & 0.0 & 0.0 \\
\hline Napot & 210 & 56.2 & 43.8 & 3.8 & 6.7 & 89.5 & 100.0 & 0.0 & 0.0 \\
\hline Tianlin $\ddagger$ & 210 & 60.0 & 40.0 & 10.0 & 0.0 & 90.0 & 97.1 & 2.9 & 0.0 \\
\hline Guizhou & 1032 & 60.4 & 39.6 & 6.0 & 4.2 & 89.8 & 98.3 & 1.6 & 0.1 \\
\hline Taijiang & 207 & 59.4 & 40.6 & 10.1 & 0.0 & 89.9 & 96.1 & 2.9 & 1.0 \\
\hline Luodian & 207 & 60.9 & 39.1 & 0.0 & 11.1 & 88.9 & 99.0 & 1.0 & 0.0 \\
\hline Changshun & 206 & 55.8 & 44.2 & 3.9 & 8.3 & 87.8 & 100.0 & 0.0 & 0.0 \\
\hline Jianhe† & 205 & 63.4 & 36.6 & 9.3 & 1.5 & 89.2 & 99.0 & 1.0 & 0.0 \\
\hline Huangpingł & 207 & 62.3 & 37.7 & 6.8 & 0.0 & 93.2 & 97.1 & 2.9 & 0.0 \\
\hline Tibet & 1007 & 52.5 & 47.5 & 0.0 & 0.5 & 99.5 & 99.4 & 0.5 & 0.1 \\
\hline Qusong & 188 & 55.9 & 44.1 & 0.0 & 0.0 & 100.0 & 100.0 & 0.0 & 0.0 \\
\hline Anduo & 199 & 49.7 & 50.3 & 0.0 & 0.5 & 99.5 & 100.0 & 0.0 & 0.0 \\
\hline GBJD & 207 & 50.2 & 49.8 & 0.0 & 1.9 & 98.1 & 99.0 & 1.0 & 0.0 \\
\hline Jiangzi† & 209 & 51.2 & 48.8 & 0.0 & 0.0 & 100.0 & 99.5 & 0.5 & 0.0 \\
\hline Nanmulin $\ddagger$ & 204 & 55.9 & 44.1 & 0.0 & 0.0 & 100.0 & 98.5 & 1.0 & 0.5 \\
\hline Shaanxi & 1044 & 56.4 & 43.6 & 11.6 & 1.4 & 87.0 & 95.9 & 4.1 & 0.0 \\
\hline Qianxian & 209 & 60.3 & 39.7 & 1.0 & 0.0 & 99.0 & 100.0 & 0.0 & 0.0 \\
\hline Fuping & 207 & 55.1 & 44.9 & 6.8 & 4.8 & 88.4 & 97.6 & 2.4 & 0.0 \\
\hline Jingbian & 209 & 54.5 & 45.5 & 16.7 & 0.0 & 83.3 & 91.4 & 8.6 & 0.0 \\
\hline Ansai† & 210 & 56.2 & 43.8 & 13.3 & 2.4 & 84.3 & 97.6 & 2.4 & 0.0 \\
\hline Yanchuan $\ddagger$ & 209 & 56.0 & 44.0 & 20.1 & 0.0 & 79.9 & 92.8 & 7.2 & 0.0 \\
\hline Total & 4129 & 56.5 & 43.5 & 6.0 & 2.9 & 91.1 & 98.1 & 1.8 & 0.1 \\
\hline
\end{tabular}

knowledge (table 5). Maternal education and age did not proceed into the final regression model. In fact, only $45 \%$ of the primary caregivers interviewed were the child's mother and most had only completed 6 years of elementary school. However, the analysis results did not change when the education variable was expanded to include all caregivers. Compared with children in Shaanxi, children in Guangxi and Guizhou were less likely to have received the four traditional EPI vaccines on time. Ethnicity also conferred a disadvantage on some groups, as did birth at home. Place of residence was not a significant influence, but there was a trend favouring children living in larger settlements over those in villages $(\mathrm{p}<0.07)$. Children whose parents had both migrated out before 12 months were less likely to have been fully vaccinated on time, as were children vaccinated at home compared to those vaccinated at village clinics or at township health facilities $(p=0.08)$. Children whose mothers/caregivers knew to report their health status to EPI staff before vaccination in 2010 were more likely to be FIC (table 5).

\section{DISCUSSION}

Just as China's public health situation has improved dramatically since the 2003 SARS crisis, China's EPI is also developing rapidly. In 2007, China introduced several new EPI vaccines to prevent meningococcal meningitis, Japanese encephalitis, hepatitis A, rubella and mumps, and long-term protection against DTP and measles using booster doses was formalised. HepB vaccine user fees were cancelled. According to China's 2012 annual report of administrative EPI data, coverage of FIC and the recently introduced $\mathrm{HAV}$ was $>95 \%$ and $>85 \%$, respectively. Coverage in western China, however, remains relatively low, as it was during the 2004 national EPI review, ${ }^{9}$ particularly for the new vaccines. ${ }^{21-23}$

Using standard methods, we found that vaccine coverage in project counties increased significantly for all antigens during the project period. It is notable that both BCG scarring and MV coverage increased in most counties, and that, in two provinces, coverage of most routine vaccines and BCG scarring was significantly higher in project reference counties than in selected non-project counties located in the same prefecture. These findings suggest that the combination of activities undertaken was successful in improving EPI access, uptake, implementation and prioritisation within project areas, and more than in non-project counties in at least two provinces (albeit with less certainty due to the absence of a formal baseline survey in non-project sites). In the two provinces where the project did not appear 
Table 3 Vaccine coverage changes across baseline (B) and final (F) surveys in project counties, and coverage differences between project and non-project counties (\%)

\begin{tabular}{|c|c|c|c|c|c|c|c|c|c|c|c|c|c|c|c|c|c|c|c|}
\hline \multirow[b]{2}{*}{ Location } & \multicolumn{2}{|c|}{$\begin{array}{l}\text { Number } \\
\text { surveyed }\end{array}$} & \multicolumn{5}{|c|}{ BCGף scar } & \multicolumn{5}{|l|}{ FICף } & \multicolumn{5}{|c|}{ Timely HepB1ๆ } & \multirow{2}{*}{$\begin{array}{l}\text { MenVף§ } \\
\text { F }\end{array}$} & \multirow{2}{*}{$\begin{array}{l}\text { HAVף§ } \\
\text { F } \\
\end{array}$} \\
\hline & $\overline{\mathbf{F}}$ & B & $\overline{\mathbf{F}}$ & B & $\Delta \eta$ & $\mathrm{CI}$ & P1ף & $\bar{F}$ & B & $\Delta$ & $\mathrm{Cl}$ & P1 & $\overline{\mathbf{F}}$ & B & $\Delta$ & $\mathrm{Cl}$ & P1 & & \\
\hline Guangxi & 836 & 852 & 95.1 & 87.1 & 8.0 & 5.3 to 10.7 & * & 92.1 & 85.8 & 6.3 & 3.3 to 9.3 & $\star \star \star *$ & 54.3 & 26.3 & 28.0 & 23.5 to 32.5 & $\star \star \star \star$ & 52.5 & 52.6 \\
\hline Donglan & 210 & 218 & 95.6 & 93.1 & 2.5 & -1.9 to 6.9 & & 89.5 & 89.0 & 0.5 & -5.4 to 6.4 & & 50.5 & 38.1 & 12.4 & 3.1 to 21.7 & $\star \star *$ & 63.3 & 14.3 \\
\hline Luocheng & 209 & 213 & 95.1 & 84.7 & 10.4 & 4.7 to 16.1 & $* * *$ & 93.8 & 83.6 & 10.2 & 4.2 to 16.2 & $* * *$ & 64.1 & 28.6 & 35.5 & 26.6 to 44.4 & $\star \star \star \star$ & 70.8 & 40.2 \\
\hline Sanjiang & 207 & 211 & 96.5 & 89.4 & 7.1 & 2.3 to 11.9 & $* *$ & 90.3 & 85.8 & 4.5 & -1.7 to 10.7 & & 54.1 & 20.9 & 33.2 & 24.5 to 41.9 & 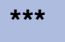 & 44.4 & 66.2 \\
\hline Napo† & 210 & 210 & 93.1 & 80.8 & 12.3 & 6.0 to 18.6 & $* * *$ & 94.8 & 84.8 & 10.0 & 4.3 to 15.7 & $* * *$ & 48.6 & 17.1 & 31.5 & 23.0 & $\star \star \star$ & 31.4 & 90 \\
\hline Tianlin $\ddagger$ & 210 & - & 91.0 & & - & & & 95.7 & - & & & & 42.4 & & - & & & 13.3 & 89 \\
\hline P2† & & & & & & & & & & & & & & & & & & $\star \star \star *$ & \\
\hline Guizhou & 825 & 840 & 95.5 & 64.3 & 31.2 & 27.7 to 34.7 & $* * *$ & 84.6 & 45.4 & 39.2 & 35.0 to 43.4 & $* * *$ & 58.9 & 10.8 & 48.1 & 44.1 to 52.1 & 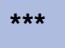 & 87.8 & 5.5 \\
\hline Taijiang & 207 & 210 & 95.6 & 87.0 & 8.6 & 3.3 to 13.9 & $* \star \star$ & 84.5 & 55.7 & 28.8 & 20.5 to 37.1 & $* * *$ & 52.2 & 13.3 & 38.9 & 30.7 to 47.1 & $\star \star *$ & 77.3 & 4.3 \\
\hline Luodian & 207 & 210 & 94.7 & 50.9 & 43.8 & 36.4 to 51.2 & 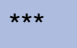 & 87.9 & 44.8 & 43.1 & 35.0 to 51.2 & $* * *$ & 61.4 & 8.6 & 52.8 & 45.2 to 60.4 & 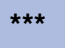 & 90.8 & 6.3 \\
\hline Changshun & 206 & 210 & 95.9 & 46.3 & 49.6 & 42.3 to 56.9 & $* \star \star$ & 86.4 & 32.9 & 53.5 & 45.6 to 61.4 & $\star \star \star *$ & 60.2 & 7.1 & 53.1 & 45.6 to 60.6 & 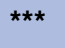 & 90.8 & 7.3 \\
\hline Jianhe† & 205 & 210 & 95.8 & 69.0 & 26.8 & 20.0 to 33.6 & 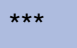 & 79.5 & 48.1 & 31.4 & 22.7 to 40.1 & $* * *$ & 62.0 & 14.3 & 47.7 & 39.5 to 55.9 & 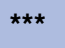 & 77.3 & 3.9 \\
\hline $\begin{array}{l}\text { Huangping } \\
\text { P2 }\end{array}$ & 207 & & 91.0 & & - & & & 78.3 & - & & & & $\begin{array}{l}43.0 \\
\star \star \star\end{array}$ & & - & & & $\underset{*}{67.5}$ & 6.7 \\
\hline Tibet & 803 & 855 & 94.0 & 91.5 & 2.5 & 0.0 & * & 69.6 & 63.6 & 6.0 & 10.5 & $\star \star$ & 44.0 & 11.5 & 32.5 & 6.5 & $\star \star * *$ & 9.0 & 42.7 \\
\hline Qusong & 188 & 218 & 95.5 & 88.2 & 7.3 & 2.1 to 12.5 & $\star \star *$ & 67.6 & 76.6 & -9.0 & -17.7 to -0.3 & * & 41.0 & 11.5 & 29.5 & 21.3 to 37.7 & $\star \star \star \star ~$ & 36.2 & 87.2 \\
\hline Anduo & 199 & 213 & 84.4 & 93.6 & -9.2 & -15.2 to -3.2 & ** & 50.3 & 21.1 & 29.2 & 20.4 to 38.0 & $\star * *$ & 46.2 & 16.4 & 29.8 & 21.3 to 38.3 & 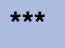 & 0.0 & 0.0 \\
\hline GBJD & 207 & 211 & 98.4 & 94.6 & 3.8 & 0.3 to 7.3 & * & 64.3 & 80.6 & -16.3 & -24.7 to -7.9 & $* \star *$ & 16.9 & 5.2 & 11.7 & 5.8 to 17.6 & $\star * *$ & 0.0 & 24.2 \\
\hline Jiangzi† & 209 & 213 & 97.0 & 89.4 & 7.6 & 2.9 to 12.3 & ** & 95.2 & 76.1 & 19.1 & 12.7 to 25.5 & $* * *$ & 71.3 & 12.7 & 58.6 & 51.0 to 66.2 & 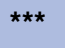 & 1.9 & 61.7 \\
\hline $\begin{array}{l}\text { Nanmulin } \ddagger \\
\text { P2 }\end{array}$ & 204 & & 75.3 & & - & & & 68.6 & - & & & & $\int_{\star \star \star}^{11.8}$ & & - & & & 0.5 & 23.7 \\
\hline Sha & 835 & 843 & 96.8 & 86.2 & 10.6 & 13.2 & $* * *$ & 96.0 & 63.8 & 32.2 & $28.7 t$ & $* * *$ & 87.9 & 56.5 & 31.4 & 27.4 & 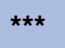 & 97.2 & 75.2 \\
\hline & 209 & 212 & 99.5 & 85.3 & 14.2 & 9.3 to 19.1 & $* * *$ & 96.2 & 68.4 & 27.8 & 21.0 to 34.6 & $* * *$ & 99.5 & 71.7 & 27.8 & 21.7 to 33.9 & $\star \star \star$ & 98.6 & 9.1 \\
\hline Fuping & 207 & 210 & 99.0 & 90.2 & 8.8 & 4.6 to 13.0 & $* * *$ & 94.2 & 62.4 & 31.8 & 24.5 to 39.1 & $* * *$ & 93.7 & 71.9 & 21.8 & 14.9 to 28.7 & $\star \star \star \star$ & 94.7 & 98.6 \\
\hline Jingbian & 209 & 210 & 92.3 & 84.8 & 7.5 & 1.4 to 13.6 & * & 98.6 & 63.3 & 35.3 & 28.6 to 42.0 & $* * *$ & 93.3 & 52.4 & 40.9 & 33.3 to 48.5 & $\star \star \star$ & 97.1 & 95.2 \\
\hline Ansai† & 210 & 211 & 96.4 & 84.7 & 11.7 & 6.2 to 17.2 & $\star \star *$ & 95.2 & 61.1 & 34.1 & 26.9 to 41.3 & $* * *$ & 65.2 & 29.9 & 35.3 & 26.4 to 44.2 & 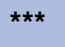 & 98.6 & 98.1 \\
\hline Yanchuan‡ & 209 & & $\underbrace{81.1}_{\star \star \star}$ & & - & & & 90.9 & - & & & & $\begin{array}{l}84.7 \\
\star \star \star\end{array}$ & & - & & & $\underbrace{89.5}_{\star \star \star}$ & $\begin{array}{l}79.0 \\
\star \star \star\end{array}$ \\
\hline $\begin{array}{l}\text { P2 } \\
\text { Totalq }\end{array}$ & 3299 & 3390 & $\begin{array}{l}* * * \\
95.4\end{array}$ & 82.5 & 12.9 & 11.4 to 14.4 & 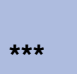 & 85.8 & 64.7 & 21.1 & 19.1 to 23.1 & $\star \star \star \star$ & $\begin{array}{l}* \star * \\
61.4\end{array}$ & 26.2 & 35.2 & 33.0 to 37.4 & 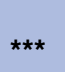 & 62 & $\begin{array}{l}* * * \\
44.1\end{array}$ \\
\hline
\end{tabular}

${ }^{*} \mathrm{p}<0.05 ;{ }^{* *} \mathrm{p}<0.01 ;{ }^{* * *} \mathrm{p}<0.001$

${ }^{*} p<0.05 ;{ }^{* \star} p<0.01 ;{ }^{* *} p<0.001$
tProject reference county.

fNon-project county.

१Total is only in the project counties; children fully immunised with the four traditional EPI vaccines (BCG, OPV, DTP and measles) by age 12 months. $\Delta$ : Absolute change in per cent EPI coverage between the B and F surveys=coverage in the final survey-coverage in baseline survey.

These vaccines were only added to China's EPI in 2008, so coverage refers only to the final survey.

$95 \% \mathrm{Cl}$ of the $\Delta ; \mathrm{B}$, baseline; DTP, diphtheria/tetanus/pertussis; EPI, Expanded Program on Immunization; F, final; FIC, fully immunised children; GBJD, Gongbujiangda; HAV, hepatitis A

vaccine; HepB1, first dose of hepatitis B vaccine; MenV, meningococcal vaccine; OPV, oral polio vaccine; P1: level of significance of difference in coverage between baseline and final surveys

within counties; P2, between the project reference and non-project counties in 2010. 
Table 4 Change of mothers'/guardians' vaccination-related knowledgef between baseline (B) and final (F) surveys in project counties, and between project and non-project counties Number

surveyed HepB1 should be given at birth? Receive EPI certificate after birth? School entry vaccination check? Observe 30 min post-vaccination?

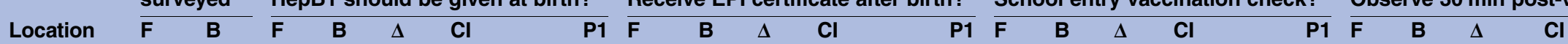

\begin{tabular}{|c|c|c|c|c|c|c|c|c|c|c|c|c|c|c|c|c|c|c|c|c|c|c|}
\hline Gu & 36 & 52 & 7.1 & 1.2 & 5.9 & 39.9 & $\star \star \star *$ & 3.4 & 7.9 & 5.5 & 39.7 & $\star \star \star *$ & 77.9 & 28.5 & 49.4 & 45.3 to 53.5 & 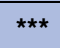 & 62.6 & 27.7 & 34.9 & 30.5 to 39.3 & *** \\
\hline onglan & 10 & 10 & 7.6 & 3.3 & 4.3 & 5.5 to 33.1 & 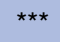 & 01 & 6.7 & 4.7 & 6.2 to 33.2 & 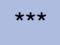 & 81.9 & 35.2 & 46.7 & 38.4 to 55.0 & $* * *$ & 62.4 & 33.3 & & 20.0 to 38.2 & ** \\
\hline & 09 & 18 & 8.7 & 4.1 & 4.6 & & t*t & if 1 & 4.1 & 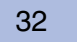 & & $* * *$ & 1.3 & 33 & 38.3 & 47.1 & $\star * *$ & 50 & 33.9 & 2.1 & & *** \\
\hline & 7 & 13 & 5.6 & 1.3 & 4.3 & 2.3 & 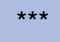 & 8 & 6.2 & 8 & & 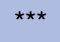 & 2.1 & 9.7 & 62.4 & & 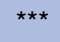 & & 12.7 & & & *** \\
\hline & & 11 & 6.7 & 6.2 & 0.5 & 7.9 & 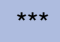 & & 4.5 & 36.5 & 5.1 & $\star \star \star ~$ & 6.2 & 26.1 & 50.1 & & $\star \star \star *$ & 66.7 & 30.8 & 35.9 & & *** \\
\hline $\begin{array}{l}\text { ian } \\
2\end{array}$ & 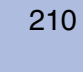 & - & ${ }_{\star \star \star \star}^{17.6}$ & - & - & & & $\begin{array}{r}69 \\
* *\end{array}$ & - & - & & & $\underset{* *}{61.9}$ & - & - & & & 31.9 & - & - & & \\
\hline & 25 & 40 & 61.5 & 3.7 & 7.8 & .9 & $* \star *$ & 87.2 & 1.9 & 2.3 & 3.2 & $\star \star * *$ & 86.9 & 37.6 & 49.3 & 3.3 & $\star \star \star *$ & 68.4 & 14.8 & & 7.6 & *** \\
\hline & & & .5 & .4 & 3.1 & & $\star * *$ & & 3.3 & 7.4 & & $* * *$ & 3 & 4.8 & 31.5 & & $\star * *$ & 8.8 & 14.8 & 34 & & *** \\
\hline & & & 5 & 4 & 1 & & $\star * *$ & & .8 & .5 & & $\star \star \star *$ & & 19.5 & 74.2 & & $\star \star * \star$ & 1.2 & 6.7 & & & *** \\
\hline & & & 8 & 1 & 5 & & ** & & & 4 & & 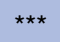 & & -8 & .7 & & 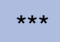 & & 19.5 & & & *** \\
\hline & & & 2.2 & 0 & 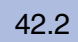 & & ** & & 47.6 & 33.9 & & * & .9 & 45.2 & 40.7 & & ** & 5 & 18.1 & 39.9 & & $\star * *$ \\
\hline nt & & 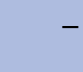 & 28 & - & - & & & ${ }_{* \star *}^{59.9}$ & - & - & & & $\underset{\star \star}{5.4}$ & - & - & & & $\underset{\star \star \star}{27.5}$ & - & - & & \\
\hline & & & 00 & 0.1 & 0.9 & & & & & & & & & 16.3 & & & . & 5.6 & 12. & & & $\star \star \star$ \\
\hline & & & 0.4 & 7.5 & 2.9 & & & & 1.7 & 5.1 & & 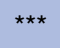 & 5 & 1.8 & 90.7 & & 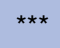 & 70.2 & 0 & 7 & & $\star \star \star *$ \\
\hline & & U & 2.3 & 59.2 & 3.1 & & * & & 31.9 & .5 & & $*$ & 8 & 11.7 & 50.1 & & $\star * *$ & 54.8 & 21.6 & S & & $\star \star * *$ \\
\hline & & 1 & 8.9 & 8.1 & 0.8 & & * & & 1.9 & 6.2 & & ** & 8 & 0 & 0.8 & & $\star \star * \star$ & 2.5 & 0 & 72.5 & & $\star * \star$ \\
\hline & & 12 & 8.1 & 1.8 & 6.3 & & $\star \star \star *$ & & .2 & 5.4 & & 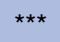 & 6 & 51.9 & 46.7 & & 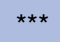 & 68.9 & 29.7 & 39.2 & & $\star * *$ \\
\hline tot & ? & 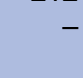 & $\underset{* \star \star}{28.1}$ & 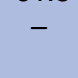 & 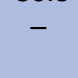 & & & $\begin{array}{l}73 \\
* \star *\end{array}$ & . & . & & & $\underset{* * *}{52.2}$ & - & 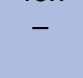 & & & 30.9 & . & . & & \\
\hline & & & 89.6 & 9.5 & $\ldots$ & & $\star \star \star *$ & & & 3 & & $\star \star \star *$ & 6.2 & & & & $\star \star \star *$ & 89.5 & 8 & & & 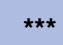 \\
\hline & 209 & 12 & 98.1 & 61.3 & 6.8 & & $* x$ & 9.5 & 7.6 & 1.9 & & & 5.7 & 28.3 & 67.4 & & & 6.7 & 32.5 & 64.2 & & $\star \star * \star$ \\
\hline & 207 & 210 & 96.6 & 51 & 5.6 & & 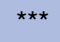 & 100 & 8.6 & 1.4 & & $\star * * x$ & 97.1 & 13.8 & 83.3 & & & 4.7 & 33.3 & 61.4 & & 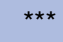 \\
\hline & 209 & & 67.5 & 38.1 & 9.4 & & 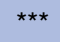 & & 4.3 & 2.8 & & ** & 4.3 & 68.6 & 25.7 & & & 9.4 & 92.9 & -23.5 & 16.4 & $\star \star *$ \\
\hline & 210 & 11 & 96.2 & 7.6 & 88.6 & 84.2 to 93.0 & 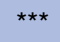 & 100 & 49.3 & 50.7 & 44.0 to 57.4 & $\star \star \star *$ & 97.6 & 41.2 & 56.4 & 49.4 to 63.4 & $\star \star \star$ & 97.1 & 19.4 & 77.7 & 71.9 to 83.5 & $* * *$ \\
\hline Janł & 208 & 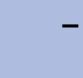 & 58.4 & - & - & & & 88.9 & - & - & & & 71.8 & - & - & & & $\underset{* \star \star}{24.4}$ & - & - & & \\
\hline otal & 297 & 3389 & 71.9 & 25.9 & 46 & 43.9 to 48.1 & $\star \star \star \star$ & 91.2 & 42.5 & 48.7 & 46.8 to 50.6 & 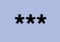 & 86.7 & 30 & 56.7 & 54.8 to 58.6 & $\star \star \star \star$ & 71.8 & 24.7 & 47.1 & 45.0 to 49.2 & $\star * \star$ \\
\hline
\end{tabular}

Total

$3297 \quad 3389 \quad 71.9$

Project reference county.

$\ddagger$ Non-project county.

ףMother/guardian gave correct response to related survey questionnaire. $\Delta$ : Absolute change of mothers'/caretakers' knowledge about vaccination=percentage in final-percentage in baseline survey.

B, baseline; EPI, Expanded Program on Immunization; F, final; GBJD, Gongbujiangda; HepB1, first dose of hepatitis B vaccine; P1, level of significance of difference in knowledge between baseline and final surveys within counties; P2, between the project and non-project counties in 2010 . 
Table 5 Factors affecting timely, full immunisation coverage* with the four traditional EPI vaccines at age 12 months

\begin{tabular}{|c|c|c|c|c|c|c|}
\hline & \multirow[b]{2}{*}{ Count } & \multirow[b]{2}{*}{ OR } & \multicolumn{2}{|c|}{$95 \%$ Cls } & \multirow[b]{2}{*}{ Wald $\chi^{2}$} & \multirow[b]{2}{*}{ p Value } \\
\hline & & & Lower & Upper & & \\
\hline Province (Shaanxi as reference) & 835 & & & & 10.57 & 0.01 \\
\hline Guangxi & 836 & 0.34 & 0.17 & 0.68 & 9.30 & $<0.01$ \\
\hline Guizhou & 25 & 0.45 & 0.23 & 0.86 & 5.76 & 0.02 \\
\hline Tibet & 801 & 0.17 & 0.01 & 2.89 & 1.51 & 0.22 \\
\hline Place of residence (village as reference) & 3011 & & & & 5.24 & 0.07 \\
\hline County & 170 & 2.06 & 0.92 & 4.59 & 3.11 & 0.08 \\
\hline Township & 118 & 2.00 & 0.84 & 4.76 & 2.44 & 0.12 \\
\hline Ethnicity (Han as reference) & 1057 & & & & 31.84 & $<0.01$ \\
\hline Tibetan & 800 & 0.75 & 0.45 & 12.51 & 0.04 & 0.84 \\
\hline Zhuang & 492 & 1.83 & 0.91 & 3.67 & 2.91 & 0.09 \\
\hline Miao & 448 & 0.47 & 0.27 & 0.84 & 6.57 & $<0.01$ \\
\hline Buyi & 210 & 0.82 & 0.42 & 1.61 & 0.33 & 0.56 \\
\hline Other (HuilMengITujia, etc) & 290 & 1.85 & 0.89 & 3.85 & 2.68 & 0.10 \\
\hline Place of birth (at home as reference) & 626 & & & & 31.84 & $<0.01$ \\
\hline County or above & 1683 & 1.86 & 1.40 & 2.48 & 18.35 & $<0.01$ \\
\hline Township-level hospital & 966 & 1.96 & 1.47 & 2.61 & 21.46 & $<0.01$ \\
\hline Private clinic & 21 & 0.48 & 0.17 & 1.35 & 1.95 & 0.16 \\
\hline Parents present for child's first year & 2443 & & & & 8.15 & 0.04 \\
\hline Father migrated out & 300 & 1.47 & 0.96 & 2.25 & 3.06 & 0.08 \\
\hline Mother migrated out & 28 & 0.65 & 0.21 & 2.00 & 0.56 & 0.45 \\
\hline Both parents migrated out & 425 & 0.71 & 0.50 & 1.00 & 3.78 & 0.05 \\
\hline Immunisation location (at home as reference) & 229 & & & & 11.96 & $<0.01$ \\
\hline County hospital & 303 & 0.77 & 0.45 & 1.33 & 0.87 & 0.35 \\
\hline Township-level hospital & 1600 & 1.44 & 0.95 & 2.17 & 3.00 & 0.08 \\
\hline Village clinic & 1093 & 1.50 & 1.06 & 2.12 & 5.36 & 0.02 \\
\hline \multicolumn{7}{|c|}{$\begin{array}{l}\text { Knowing to inform EPI staff of child's health status at vaccination time (not knowing as reference) } \\
220\end{array}$} \\
\hline & 3077 & 1.84 & 1.31 & 2.59 & 12.18 & $<0.01$ \\
\hline
\end{tabular}

to influence routine vaccine coverage, the EPI had also benefited from substantive non-project input during the same period; indeed, many of the same strategies used in this project were also introduced throughout Guizhou. ${ }^{15} 2425$ Campaign-related activities also explain the widely varying baseline measles incidence in Guizhou and Shaanxi. However, in all provinces, a large project benefit was observed on coverage with HepB1 and the three new vaccines assessed, in 2010. Higher coverage with these new vaccines in the 16 project counties is most likely related to project activities, as they were only introduced in 2008.

In addition, the knowledge of caregivers increased significantly over the course of the project, and was much higher in project reference counties than in non-project counties in 2010. Given the relatively low rates of knowledge for many of the knowledge variables at baseline, and at follow-up in non-project counties, we confidently attributed the observed differences to project inputs. Indeed, knowledge in non-project counties in 2010 was rather weak, even related to the НерB birth dose that has been available in China since 2002. However, although higher than at baseline, knowledge also remained low for many variables in some project counties. Although a variety of locally adapted EPI promotion activities were implemented using various media, face-to-face communication and active participation by community members, they seem to have improved EPI-related participation and behaviour more than knowledge.

Our two surveys provide rare, semi-independent subnational data on EPI coverage in China. In spite of China's great achievements in disease control and generally high EPI coverage, it is apparent that many children are not fully protected against vaccine-preventable diseases, especially in remote areas. This is also true among migrant children in urban areas. ${ }^{26}$ Unvaccinated children carry a higher risk of disease and transmission of disease to others, as experienced when imported poliovirus reappeared in Xinjiang in 2011. ${ }^{11}$ According to unpublished UNICEF assessments, in that outbreak, low household awareness of and participation in the EPI resulted in low OPV coverage. There remains, therefore, an ongoing need to identify affordable and feasible strategies to ensure timely EPI coverage throughout China. From our evaluation, we conclude that this is particularly important when new antigens are introduced.

Our findings provide a foundation for recommending this project's approach in poor rural areas of China and elsewhere. In addition to promotion of hospital delivery, 
which was successful in project and non-project counties and is known to improve timely HepB1, ${ }^{10}{ }^{27-30}$ the project focused on improving knowledge among both, the community and EPI workers, and improving service standards and equipment. Moreover, it promoted multisectoral engagement in the EPI through involvement of several non-health sectors. Given the project's greater influence on HepB1 coverage (despite similar hospital delivery rates) and on new vaccine coverage than on traditional vaccine coverage, this may have been a key factor in increasing the prioritisation of the EPI in project counties. Multisectoral engagement included establishment of a leadership group comprising representatives of the local governor and health, education and migration management offices, widening stakeholder participation in promoting, planning, managing and implementing the EPI. This has been reported elsewhere in Guizhou. ${ }^{15}$ In our project provinces, the local government and education bureaus issued related documents and a multisector working mechanism was developed; EPI implementation was incorporated into government performance appraisal indicators. The observed improvement in mothers'/caregivers' knowledge of kindergarten-entry and school-entry EPI certificate checking verifies the participation of the education system. Given China's virtually universal school enrolment, annual school-entry checking, if implemented, should prove effective in reducing the proportion of children and adolescents unprotected against vaccine-preventable diseases, a major cause of ongoing measles transmission.

The findings also enable recommendation of vaccination at a scheduled EPI service as opposed to at home (again verifying earlier findings ${ }^{10} 15$ ), and ensuring the EPI-related knowledge of caregivers of children left behind by out-migrating parents, as also found in Qinghai province. ${ }^{31}$

Some limitations and other issues pertaining to the study merit discussion. First, we compared only one project and one non-project county in each province. EPI performance in all counties in 2004 was only based on administrative data; although 2004 administrative coverage in project counties was similar to surveyed coverage in 2006, administrative coverage can be unreliable in poor rural areas, so selection of a non-project county relied on provincial authorities' overall perspectives on county EPI staff performance, as well as more objective population and economic data. This was the best alternative to including more non-project counties or surveying non-project counties at baseline, neither of which was possible. We fully acknowledge that the project's impact on routine vaccine coverage is epidemiologically tenuous due to the lack of equivalent survey data from non-project areas at baseline, but on balance feel the evidence allows confidence in our interpretation. Second, in addition to parallel, EPI-focused initiatives in Guangxi and Guizhou, ${ }^{15} 2425$ non-project counties would have benefited from secular health system strengthening in China, which was likely to have indirectly improved the EPI, ${ }^{32} 33$ so the evaluation did not assess project impact in isolation. Although it is difficult to generalise from one reference and one nonproject county, given that these secular improvements benefited all counties, we conclude that the observed better performance on traditional vaccine coverage in Tibet and Shaanxi, and on HepB1 and most new vaccine coverage and also on caregiver knowledge in all four provinces, is almost certainly a direct result of the project. Finally, we note that, while in most cases the non-project county EPI coverage was similar to or above that found among the four project counties in each province, by the end of the project it was lower, again suggesting the interventions' influence.

Third, some children's parents were away during the survey, which was then answered by less knowledgeable grandparents or other caregivers. This would have biased improvements in project counties down, as ruralurban migration in China has increased since baseline and more children are now left behind with elderly caregivers.

Finally, as with any project, the observed improvements may not be sustained and it has been almost 5 years since the project was completed. However, vaccination has been a high priority in China for decades, and continues to be supported at high levels of government; evaluations such as this one provide good material for advocacy and publicity. The additional US $\$ 14000$ provided per county per year (excluding funds provided by local government) was a small investment in counties averaging a population of 250000 and with various sources of EPI funding. These include central and local government funding, ad hoc project funding (for campaigns, etc), separate funding for infrastructure, manpower, coverage monitoring and disease surveillance, vaccine and syringe procurement, cold chain maintenance, etc. In this context, and given possible inputs from the other sectors engaged, project inputs were inexpensive and should be replicable. The EPI target cohort in each province is small, at approximately $1.4 \%$ of the total population in provinces with a high population of ethnic minorities (such as Tibet, Guizhou and Guangxi), and only $1.2 \%$ in Han-dominant provinces (such as Shaanxi), again limiting the related cost of the programme.

We conclude that some counties in western China perform relatively poorly on the EPI, but vaccination coverage in these areas can be improved with a relatively simple and inexpensive set of activities. In addition to communications, EPI-specific training and service strengthening, a key element of the successful approach implemented may have been engaging with related government departments and elevating the priority given to the programme by local leaders.

\section{Author affiliations}

${ }^{1}$ National Immunization Program, Chinese Centre for Disease Control and Prevention, Beijing, People's Republic of China

${ }^{2}$ Peking University Health Science Centre, Beijing, People's Republic of China 
${ }^{3}$ UNICEF China Country Office, Beijing, People's Republic of China

${ }^{4}$ UNICEF Headquarters, New York, New York, USA

Acknowledgements The authors gratefully acknowledge support for the surveys provided by staff in the four project provinces and 20 surveyed counties, and Dr Lance Rodewald (WHO Beijing) for helpful comments on earlier versions of this report.

Contributors $\mathrm{YZ}, \mathrm{YX}, \mathrm{XZ}, \mathrm{XL}$ and $\mathrm{DH}$ designed the study. $\mathrm{YZ}, \mathrm{YX}, \mathrm{XZ}$ and $\mathrm{CY}$ conducted the field work and surveys. $\mathrm{DH}, \mathrm{YX}$ and $\mathrm{YZ}$ wrote the paper. All the authors agreed to submission of the manuscript for publication.

Funding This evaluation was funded by UNICEF China.

Competing interests None declared.

Ethics approval China CDC and county authorities at the project sites.

Provenance and peer review Not commissioned; externally peer reviewed.

Data sharing statement No additional data are available.

Open Access This is an Open Access article distributed in accordance with the Creative Commons Attribution Non Commercial (CC BY-NC 4.0) license, which permits others to distribute, remix, adapt, build upon this work noncommercially, and license their derivative works on different terms, provided the original work is properly cited and the use is non-commercial. See: http:// creativecommons.org/licenses/by-nc/4.0/

\section{REFERENCES}

1. World Health Organization. Global routine vaccination coverage, 2010. Wkly Epidemiol Rec 2011;86:509-13.

2. Centers for Disease Control and Prevention. Progress toward interruption of wild poliovirus transmission-worldwide, January 2011-March 2012. MMWR Morb Mortal Wkly Rep 2012;61:353-7.

3. Roper MH, Vandelaer JH, Gasse FL. Maternal and neonatal tetanus. Lancet 2007;370:1947-59.

4. Liu L, Johnson HL, Cousens S, et al. Global, regional, and national causes of child mortality: an updated systematic analysis for 2010 with time trends since 2000. Lancet 2012;379:2151-61.

5. Liang XF, Wu ZL. Implementation of EPI for 30 years to protect hundreds of millions of people's health. Chin J Prev Med 2008;42 (Suppl.):4-6.

6. Zheng J, Zhou Y, Wang $\mathrm{H}$, et al. The role of the China Experts Advisory Committee on Immunization Program. Vaccine 2010;28 (Suppl 1):A84-7.

7. Hipgrave D, Guo S, Mu Y, et al. Chinese-style decentralization and health system reform. PLoS Med 2012;9:e1001337.

8. Hipgrave D. Communicable disease control in China: from Mao to now. J Glob Health 2011:1:223-37.

9. Ministry of Health. The Report of China's National EPI Review in 2004. Beijing: Ministry of Health, 2005.

10. Zhou $\mathrm{Y}$, Wang $\mathrm{H}$, Zheng J, et al. Coverage of and influences on timely administration of hepatitis $B$ vaccine birth dose in remote rural areas of the People's Republic of China. Am J Trop Med Hyg 2009;81:869-74.

11. Luo $H M$, Zhang $Y$, Wang $X Q$, et al. Identification and control of a poliomyelitis outbreak in Xinjiang, China. $N$ Engl J Med 2013;369:1981-90.
12. National Bureau of Statistics. China Statistical Yearbooks. Beijing, Published annually.

13. Wang $Y$, Wang $Y$, Zhang J. Evaluation on efficacy of IEC strategy on child immunization in Guizhou province. Chin Public Health 2007:11:1390-2.

14. Chee G, Pielemeier N, Lion A, et al. Why differentiating between health system support and health system strengthening is needed. Int J Health Plann Manage 2013;28:85-94.

15. Du W, Zhu Q, Dong YB, et al. Evaluation of the implementation effect on strengthening routine immunization service in minority areas of Guizhou province. Appl Prev Med 2009;15:134-6.

16. World Health Organization. Introduction of Hepatitis $B$ Vaccine into Childhood Immunization Services. Geneva: WHO, 2009.

17. World Health Organization and UNICEF. GIVS: Global immunization vision and strategy 2006-2015. Geneva: World Health Organization, 2005.

18. Expanded Programme on Immunization of the Department of Immunization Vaccines and Biologicals. Immunization in practice: a practical guide for health staff. Geneva: WHO, 2004.

19. Feng XL, Shi G, Wang Y, et al. An impact evaluation of the Safe Motherhood Program in China. Health Econ 2010;19(Suppl): 69-94.

20. WHO Department of Vaccines and Biologicals. Immunization coverage cluster survey—reference manual. Geneva: World Health Organization, 2005.

21. Centers for Disease Control and Prevention. Progress in hepatitis B prevention through universal infant vaccination-China, 1997-2006. MMWR Morb Mortal Wkly Rep 2007;56:441-5.

22. Hu GL, Guo SC, Tu QF, et al. The situation of the expanding program on immunization in Jiangxi province in 2009. Chin J Vaccin Immun 2012;18:153-7.

23. Zheng HR, Liu QL, Guan XJ, et al. Implementation analysis on the expanded program on immunization in Sichuan province in 2010. Chin J Vaccin Immun 2012:18:158-61.

24. Zhuo J, Geng W, Hoekstra EJ, et al. Impact of supplementary immunization activities in measles-endemic areas: a case study from Guangxi, China. J Infect Dis 2011;204(Suppl 1):S455-62.

25. World Health Organization Western Pacific Regional Office. A model of success in measles elimination: the Guizhou measles project in China. WHO WPRO Measles Rubella Bull 2011;5:9.

26. Liu DW, Sun MP, Liu WX, et al. Comparative study on immunization coverage rates of nine vaccines between local and floating children. Chin J Vaccin Immun 2007;13:165-9.

27. Murakami H, Van Cuong N, Huynh L, et al. Implementation of and costs associated with providing a birth-dose of hepatitis $B$ vaccine in Viet Nam. Vaccine 2008;26:1411-19.

28. Li XM. Newborns' first dose of hepatitis B vaccine situation analysis. China Med Pharm 2011:1:167-8.

29. Huang YL, Shi F, Wang F, et al. Investigation on hepatitis B vaccination among 1-1.5 year-old children in Karamay City, 20072009. Prev Med Tribune 2011;17:617-23.

30. Creati M, Saleh A, Ruff TA, et al. Implementing the birth dose of hepatitis B vaccine in rural Indonesia. Vaccine 2007;25: 5985-93.

31. Zhang JX, Huang LP, Kang CY, et al. Attitudes toward and practice of childhood immunization in Qinghai province. Chin Prim Health Care 2005; 19:52-3.

32. Meng Q, Xu L, Zhang $\mathrm{Y}$, et al. Trends in access to health services and financial protection in China between 2003 and 2011: a cross-sectional study. Lancet 2012;379:805-14.

33. Yip WC-M, Hsiao WC, Chen W, et al. Early appraisal of China's huge and complex health-care reforms. Lancet 2012;379:833-42. 